\title{
Effect of an Educational Intervention on Self-Care Practices among Patients with Diabetic Retinopathy
}

\author{
Marwa Ezzat Al baiuomy Shaban \\ Medical-Surgical Nursing, Faculty of Nursing, Alexandria University \\ Yousria Mohamed Salem, Professor \\ Medical-Surgical Nursing, Faculty of Nursing, Alexandria University \\ Nabila Ahmed Bedier, Professor \\ Medical-Surgical Nursing, Faculty of Nursing, Alexandria University \\ Mervat Adham Ghaleb, Professor \\ Medical-Surgical Nursing, Faculty of Nursing, Alexandria University \\ Mohsen Ahmed Abou Shousha, Professor \\ Ophthalmology, Faculty of Medicine, Alexandria University
}

\begin{abstract}
Background: Diabetic retinopathy (DR) is the most common ophthalmic complications of diabetes mellitus (DM) and is one of the leading causes of vision impairment and vision loss. Timely intervention, and self-care practices measures can delay or prevent subsequent loss of vision. Objective: This study aimed to evaluate the effect of an educational intervention on self-care practices among patients with diabetic retinopathy. Setting: The study was conducted at Vitreoretinal Outpatient Clinic at Alexandria Main University Hospital, Alexandria, Egypt. Subjects: A convenience sample of 60 adult patients with DR. Tools: Three tools were used for data collection: Tool I: Patients' Bio-socio demographic Data Structured Interview Schedule. Tool II: Diabetic Retinopathy Patient's Knowledge Assessment Questionnaire to assess patients' knowledge related to DR. Tool III: Self-Care Practices Structured Interview Schedule to assess self-care practices undertaken by the patients. Results: The study group showed marked improvement post-self-care practices educational intervention application where all of the study group had good overall self-care practices than control group. Conclusion: The studied patients who received self-care practices educational intervention had significant improvement of knowledge and self-care practices than those who didn't receive it. Recommendations: In-service training programs and continuing education sessions have to be provided for nurses about diabetic retinopathy, its complications, treatment modalities, and nursing management
\end{abstract}

Keywords: Diabetic Retinopathy, Self-Care Practices, Nursing Educational Intervention.

\section{Introduction}

Diabetic retinopathy (DR) is the most common ophthalmic complication of DM and is one of the leading causes of vision impairment and vision loss (Wong \& Sabanayagam, 2019). It can be defined as a chronic progressive, potentially sightthreatening disease of the retinal microvasculature accompanied by prolonged hyperglycemia (Sabanayagam et al., 2018). Worldwide, nearly $35.4 \%$ of diabetic patients have DR, of which a third have sight-threatening DR and 7.6\% macular edema (Lee et al., 2015).

The severity and progression of DR are strongly associated with prolonged duration of DM, poor glycemic control, hypertension, and hyperlipidemia (Baumal \& Duker, 2018). DR can progress in four stages, which proceed from mild, moderate, and severe non-proliferative to proliferative diabetic 
retinopathy (Kumar et al., 2012). In this regard, DR is usually

associated with blurred vision, floaters, poor night vision, sudden and total loss of vision (American Academy of Ophthalmology, 2021; National Eye Institute, 2019). DR has been well reported to involve several complications such as vitreous hemorrhage, glaucoma, macular edema, retinal detachment, and vision loss (Imai et al., 2011). Treatment of DR includes intravitreal injections, laser surgery, and vitrectomy (Mitchell \& Wong, 2014). Self-care practices management is vital to control DR and prevent its complications (Funnell et al., 2012). So, ophthalmic nurse educator plays an important role to ensure DR patient attain competency and adherence to long-term self-care practices management. As well, the patient should initiate and sustain a complex selection of self-care practices including eye care, self-monitoring blood glucose levels, periodic health checkups, proper intake of medications, dietary intake, and physical activity (American Academy of Ophthalmology, 2014).

\section{Significance of the study:}

One of the most ocular complications of diabetes mellitus is diabetic retinopathy with a high risk of severe vision impairment among $10 \%$ of patients, which increases with the duration of diabetes. Therefore, 20 years after diagnosis, most patients will have some degree of DR. These complications can lead to severe adverse effects including loss of vision which means physical disability, depression, a high financial burden, and low quality of life (Rodriguez et al., 2020).

To overcome the war on diabetic retinopathy, a paradigm shift in strategic focus and resources must be made from such tertiary treatment toward primary and secondary prevention, which are more impactful, broader, and cost-effective for the larger population. These include enhancing education and awareness of the risk of DR and its complications among patients, promoting behavioral modifications such as physical activity and medication compliance and control of blood pressure, setting up systematic screening programs for DR to detect its progression, and implementing cost-effective, evidence-based policies and guidelines for managing DR (Wong \& Sabanayagam, 2019).

Since effective long-term treatment of DR is difficult, time-consuming, and costly their prevention is very important. It is, therefore, essential to develop educational intervention on self-care practices among patients with DR to encourage them to improve their knowledge and practices toward DR and prevention of further complications.

\section{Aims of the Study}

This study aimed to evaluate the effect of an educational intervention on selfcare practices among patients with DR.

\section{Hypothesis of the study}

Diabetic retinopathy patients who receive educational intervention exhibit improvement in self-care practices than those patients who do not receive it.

\section{Materials and Method}

\section{Materials}

Research design: A quasi-experimental research design was utilized in this study.

Setting: The study was conducted at Vitreoretinal Outpatient Clinic at Alexandria Main University Hospital, Alexandria, Egypt.

Subjects: A convenience sample of 60 adult patients with DR from the above-mentioned setting was included in the study.

The study subjects were divided randomly into two equal groups; control and study group(30 for each group), the control group exposed to routine care only, and the study group received an educational intervention.

Tools of the study: Three tools were used for data collection:

The tool I: Patients' Bio-socio demographic Data Structured Interview Schedule: This tool was developed by the researcher to 
collect socio-demographic and clinical data. It consisted of two parts:

Part I: Socio-demographic data: This part included information about the study patients' general characteristics: age, gender and level of education, area of residence, marital status, occupation, monthly income, treatment system, and health care provider at home.

Part II: Clinical data: This part included information about:

- Family history about having diabetes mellitus, diabetic retinopathy, and its complications.

- Patient's past medical history; complaint of other chronic diseases, previous hospitalization and its causes, type of diabetes, and time since seeking medical help.

- Present history; onset of diabetic retinopathy, chief complaints, the occurrence of complications of diabetic retinopathy, and prescribed medications.

Tool II: Diabetic Retinopathy Patient's Knowledge Assessment Questionnaire: This tool was developed by the researcher based on relevant recent literature (American Diabetes Association, 2019; American Optometric Association, 2019; Deak et al., 2015; The Royal College of Ophthalmologists, 2012) to assess patients' knowledge related to DR. It included a group of MCQ questions.

Patients' knowledge answers were scored as (3) for a correct and complete answer, scored as (2) for a correct and incomplete answer, and scored as (1) for incorrect answer.

Scoring System: The total score was summed up and was converted into a percentage. Patients' knowledge was evaluated as the following:

Those who have a knowledge $\%$ score (66.6\% and more) were categorized as having a good knowledge level.

- Those who have a knowledge \% score $(33.3<66.6 \%)$ were categorized as having satisfactory knowledge levels.
- Those who have a knowledge \% score below $(33.3 \%)$ were categorized as having poor knowledge levels.

Tool III: Self-Care Practices Structured Interview Schedule: It was developed in Arabic by the researcher based on relevant recent literature (Albikawi \& Abuadas, 2015; American Diabetes Association, 2014; American Diabetes Association, 2019; American Diabetes Association, 2020; Al Shibli et al., 2018; Bhavsar \& Khardori, 2020; Dai et al., 2019; Demmitt, 2015; Diabetes State/Territory Organizations, 2012; Duffy, 2017; Harkins, 2008; International Centre for Eye Public Health,2016; Jesus,2012; NHS， 2021; Nordqvist, 2015; The International Council of Ophthalmology, 2017; The Johns Hopkins University, 2021; Viswanath \& McGavin, 2003; Weinstock, 2020; WHO, 2013) and was used to assess self-care practices undertaken by the patients related to the following items:

Eye care included (16) statements related to the periodic follow up \& examine eye fundus regularly, report of an ophthalmologist for any unusual conditions, the regular wearing of eyeglasses, regular checkup on the eyeglasses, wear dark glasses, adjust lighting, keep a visual acuity test and technique of administration of eye medications.

Self-monitoring of glucose in the blood included (7) statements related to the monitoring of blood glucose level monthly, regular monitoring of glycosylated hemoglobin (HbA1c), asking others for help in monitoring glucose, causes of not monitoring of blood glucose levels, and regular follow up and discuss results of findings with a physician.

Periodic health checkups included (5) statements regarding checkups yearly, regular monitoring of blood pressure, a regular check of blood lipid, and causes of not following up with the doctor. 
Proper intake of medications included (8) statements regarding adherence to a therapeutic regimen of diabetes mellitus and eye, asking others for help in preparing insulin, adaptive techniques in taking medications, taking eye medications or not in case of forgetting the medication dose, and regular intake of appropriate treatment in case of coughing

Dietary intake included (9) statements related to compliance with therapeutic diet, intake of herbs, cause of eating fibers, cause of intake of a low-fat diet, cause of intake of low salt diet, consume food containing Vit A, Vit C \& Zinc, and causes of follow up with a dietitian.

Physical activity included (16) statements regarding the moderate performance of daily living activities, asking others for help in performing daily living activities, performing exercise regularly, cause of not performing exercises, avoiding activities that need forward bending, avoiding heavy lifting, Use aids such as "cane, stick" or ask others for help to move, adaptive techniques in performing daily living activities, keep floors always dry, Increase light for up and down the stair, wear the prescribed glass or the magnifying glass when reading newspapers, magazines and watching television, wear prescribed glasses when doing work that requires eye focusing, decrease the number of working hours, not make any effort in work and ask others for help as needed in the work

Scoring System: The patients' practices were evaluated as the following:

- Scoring of $66.6 \%$ and more of the total self-care practice score was considered good.

- $33.3<66.6 \%$ of the total self-care practice score was considered fair.

- Below $33.3 \%$ of the total self-care practice score was considered poor.

\section{Method}

An official letter was sent from the Faculty of Nursing, Alexandria University to responsible authorities of the selected setting to obtain their approval to collect the data after explaining the aim of the study.

Tool I, II, III were developed by the researcher based on the relevant recent literature in a simple Arabic language.

Validity: A jury of five experts specialized in the field of Medical-Surgical Nursing and Ophthalmology at Alexandria University, was consulted to test content validity of the study, completeness, and clarity of items. Then, the necessary modifications were done, accordingly.

Reliability: The developed tools was tested by using Cronbach's Alpha test. The reliability coefficient value for knowledge was 0.969 while; reliability coefficient value for self-care practices was 0.965 .

A Pilot study was conducted on 10 patients from the previously mentioned settings to test clarity, feasibility, the applicability of the tools, and necessary modifications were done. Those patients were excluded from the actual sample.

- Data collection: The study was conducted in four phases as the following:

Phase I: Assessment phase: Initial assessment of these patients (control\& study groups) was carried out before the educational intervention using tools I, II and III, to collect the needed data, clinical data, assess existing knowledge and self-care practices as well as, assessing the patients' needs before developing the educational intervention.

Phase II: Planning and developing of the intervention phase: The content of the educational intervention covered knowledge of DR \& 6 items related to eye care, selfmonitoring of glucose in the blood, periodic health checkups, proper intake of 
medications, dietary intake as well as, physical activity.

Phase III: Implementation of the intervention phase: The developed self-care practices educational intervention was conducted and applied individually to each patient through face-to-face lectures and also PowerPoint slides and was supported by using a written booklet.

- The educational intervention was conducted in 2 sessions. The first session was carried out during the assessment phase; while the second session was carried out in the next month. Each session continued for 45-60 minutes.

- The self-care practices educational intervention consisted of the following two sessions:

*The first session contents included the following:

- Specification of the objectives.

- Instruct the patients about the information related to the disease (definition, signs \& symptoms, and risk factors for developing diabetic retinopathy).

- Demonstration and re-demonstration for the patient and/or family member about eye care and physical activity.

- Give the patients instructions about dietary intake using images.

* The second session included:

- Provide the patients with the following information:

- Complications of diabetic retinopathy, methods of treatment, self-care of diabetic retinopathy, and prevention of complications of diabetic retinopathy).

- Give the patients instructions about proper intake of medications and how to prevent medication errors at home.

- Give the patients instructions about periodic health checkups, how to follow-up, and register the outcomes of follow-up.

- Demonstration and re-demonstration of selfmonitoring of glucose in the blood. Also, explain the record of blood glucose tests for the patient to document the results of tests following each session.
- Patients were asked to repeat the knowledge learned several times until the researcher make sure that the given knowledge was successfully mastered in the two sessions.

- Patients were asked to repeat the educational intervention until the investigator was assured that the patient had mastered selfcare practices.

- Reinforcement for patients and answering any patients' questions.

Give time to patients to read and understand the information included in the illustrative booklet which was given to each patient in the study as a reference from the beginning of the first session of educational intervention. Then the researcher clarifies any questions and information if needed post sessions.

- Follow up of patients by phone call every week for correction of any mistakes, answer patients' questions and reinforcement of the given information due to presence of covid 19.

- Follow-up checks which include monitoring of blood glucose, HbA1c, blood lipid, routine medical examination for teeth, kidney, and eye and blood pressure measurement.

Phase IV: Evaluation phase: Evaluation was done in two phases as follow:

Phase I: This phase was carried out during the assessment phase (pre-test for both control and study group using tools II and III).

Phase II: every patient recruited in both groups followed after three months of the first session using the tool II, and III as a post-test to evaluate the effect of the educational intervention on self-care practices among patients with DR

Data collection: Data was collected for a period of 5 months starting from January 2021 to May 2021.

\section{Ethical considerations:}

An informed written consent was obtained from each study subject after explanation of the 
study purpose. Anonymity and privacy of the study subjects, confidentiality of the collected data, and the subject's right to withdraw at any time were maintained.

\section{Statistical Analysis}

Data were fed to the computer and analyzed using IBM SPSS software package version 20.0. (Armonk, NY: IBM Corp). Qualitative data were described using numbers and percentages and quantitative data were described using range (minimum and maximum), mean, standard deviation, and median. The significance of the obtained results was judged at the 5\% level. The tests used were

Chi-square test: For categorical variables, to compare between different groups.

Fisher's Exact or Monte Carlo correction: Correction for chi-square when more than $20 \%$ of the cells have expected count less than 5 .

Marginal Homogeneity test: For categorical variables, to compare between two periods.

Student t-test: For normally distributed quantitative variables, to compare between two studied groups.

Mann Whitney test: For abnormally distributed quantitative variables, to compare between two studied groups.

Paired t-test: For normally distributed quantitative variables, to compare between two periods.

Wilcoxon signed ranks test: For abnormally distributed quantitative variables, to compare between two periods.

McNemar test: Used to analyze the significance between the different stages.

\section{Results}

Table (1) Shows the frequency distribution of the control and study group patients with DR according to their socio-demographic data, the vast majority of both control and study group patients $(96.7 \%, 80 \%)$, respectively their age ranged from 50 to $\geq 60$ years. Nearly threequarters of the control and study group patients $(73.3 \%, 73.3 \%)$, respectively were females. The highest percentage of both control and study group patients $(43.3 \%, 26.7 \%)$, respectively were illiterate. Also, $76.7 \%$ of the control group patients and $70 \%$ of the study group patients were married. There were no statistically significant differences between both groups concerning their sociodemographic data.

Table (2) Shows the frequency distribution of the control and study groups according to their clinical data: concerning family history, nearly two-thirds of the control group (62.2\%) their mother had DR; while the majority of the study group $(77.8 \%)$ their brother/sister had DR. Regarding past health history, about twothirds of the control and study groups were having type I diabetes mellitus $(63.3 \%, 60 \%)$, respectively. Regarding present history, the majority of both control and study groups (80\%, 70\%), respectively have DM for 15 years and more. Over three-quarters of both the control and study groups were complaining of blurred vision $(76.7 \%, 83.3 \%)$, respectively .

Table (3) Reveals a comparison between the control and study group patients with DR according to total patients' knowledge mean percent scores pre, and post implementation of self-care practices educational intervention, all of the control and study groups $(100 \%, 100 \%)$, respectively had poor total knowledge about DR pre-self-care practices educational intervention application with no statistically, significant difference between the two groups. However, there was a marked improvement in the knowledge within the study group postself-care practices educational intervention than control group with a statistically significant difference between two groups $(p<0.001 *)$.Also, there was statistically, significant difference within study group pre, and post-self-care practices educational intervention application $(\mathrm{p}<0.001 *)$. 
Table (4) Shows a comparison between the control and study groups regarding overall self-care practices mean percent scores pre, and post implementation of self-care practices educational intervention: It was observed that the majority of both control and study group patients $(93.3 \%, 96.7 \%)$, respectively had fair overall self-care practices pre-implementation of self-care practices educational intervention with no statistically significant difference between the two groups. However, the study group showed marked improvement post-selfcare practices educational intervention application where all of the study group $(100 \%)$ had good overall self-care practices with a statistically, significant difference between the two groups $(\mathrm{p}<0.001 *)$. Also, the higher statistically, significant difference was found within study group pre, and post-selfcare practices of the educational intervention application $(\mathrm{p}<0.001 *)$. Regarding overall practices mean percent score, it was denoted that the Mean \pm SD for the control group was $39.58 \pm 5.64$ and the study group was $44.96 \pm$ 8.75 pre-implementation of self-care practices educational intervention with no statistically, significant difference between the two groups. While; post-self-care practices educational intervention application a great improvement observed where the Mean \pm SD for the study group changed to be $83.84 \pm 5.67$ with a statistically, significant difference between the two groups $\left(\mathrm{p}<0.001^{*}\right)$.

\section{Discussion}

A significant element towards optimal management of diabetic retinopathy is the improvement of awareness, knowledge, and education about self-care practices (Al Zarea, 2016). So, patient teaching is an important role for nurses, although it may be difficult, change can lead to control of DR, its complications and improve quality of life when patients adopt healthier lifestyle choices (Wood, 2010).

Concerning socio-demographic and clinical data of the studied diabetic retinopathy patients, regarding age, the results of the present study revealed that the vast majority of the control and study group patients were in the age group ranging from 50 to $\geq 60$ years. This could be justified by that, the majority of both studied groups having DM for 15 years and more with poor control of DM which are a risk for developing long term complications including DR. This finding was in agreement with Albaiuomy et al. (2019) who found that the majority of the DR patients were in the age group from 50 to 60 years.

Concerning gender, the finding of the present study indicated that female patients comprised a higher population than males. This may be due to that majority of both groups were housewives and didn't have health insurance subsequently they get their health care services through free hospitals. This finding was in agreement with Hartayu et al. (2012) who found that the majority of participants in all groups are females. These findings contradicted the findings of Najee \& Shakir (2019) who reported that the highest percentage for both control and study group patients were males.

As regards the level of education, the finding of the present study showed that the highest percentage of both control and study group patients were illiterate. It may be due to a lack of awareness about the importance of education and didn't care to be educated in the past. This finding was similar to Mohamed et al. (2019) who found that $40 \%$ of studied group patients were illiterate.

In the current study, it was noticed that nearly three-quarters of both groups were married. The interpretation as reported by patients may be related to that, most of the studied patients were females who have too much house working and responsibilities which can lead to ignoring adoption of healthy lifestyles that led to increased risk for diabetic retinopathy development and progression. This finding was in the same line with Mohamed et al. (2019) who emphasized that the vast majority of studied groups with DR were married. 
Moreover, it was noticed that there were no statistically, significant differences were found between both groups concerning their socio-demographic data which reflect that the only factor affecting the study results was the implementation of self-care practices educational intervention.

Concerning past \& present health history, the present study showed that about two-thirds of both control and study groups were having type I diabetes mellitus. This may be due to the majority of the studied groups have had diabetes mellitus for 15 years and more. Also, it may be related to pathophysiological changes of retina due to long duration of DM. This finding disagreed with Khalaf et al. (2019) who found that nearly two-thirds of studied retinopathy patients suffered from type II diabetes mellitus. Concerning the patient's duration of diabetes mellitus, the present study revealed that the majority of both control and study groups have had diabetes mellitus for 15 years and more. This result agrees with Macky et al. (2011) who found that the majority of patients have longer diabetes disease duration. This finding contradicted with Achigbu et al. (2016) who expressed that, majority of their studied patients had been diagnosed as diabetic for 5 years or less before having retinopathy .

Concerning patients' total knowledge score about diabetic retinopathy preimplementation of self-care practices educational intervention, all of the control and study groups had poor total knowledge about diabetic retinopathy disease. This can be explained by the fact that This may be explained by the fact that the highest percentage of the studied patients were illiterate, married \& housewives. Also, it may be due to lack of time for health care providers to provide health education about DR. This finding was in the same line with Hosseini et al. (2021) who expressed that, the participants' knowledge about diabetic retinopathy was poor before the implementation of their educational program.
Regarding post-implementation of selfcare practices educational intervention, the results of the current study showed that more than three-quarters of the study group had a good total knowledge score and the minority of them had satisfactory knowledge. This improvement in patient's knowledge may be due to the use of different teaching strategies as lecture, discussion, a colored booklet, and data show presentation, in addition to the researcher's reinforcement of information received at the end of each session and pre the next session together with adherence of the study group to the given instructions regarding diabetic retinopathy. These findings were matched with Duan et al. (2017) who stated that the majority of participants' knowledge about diabetic retinopathy improved after the intervention. This comes in contrast with Najee \& Shakir (2019) who found that diabetic retinopathy knowledge has decreased after three months post-implementation of the educational program.

Furthermore, there was a highly statistically, significant difference within study group pre, and post-self-care practices educational intervention application. These results mean that the patients have got many benefits from the educational intervention. This finding was similar to Hazavehei et al. (2010) who illustrated that the knowledge was significantly increased in the experimental group compared to the control group after intervention.

Concerning overall self-care practices, the present study results indicated that no significant difference was found between both studied groups' overall self-care practices as the majority of both control and study group patients had fair overall self-care practices pre-implementation of self-care practices educational intervention. This may be explained by the fact that patients' didn't have enough information about diabetic retinopathy self-care practices.

However, the study group showed marked improvement post-self-care practices 
educational intervention application where all of the study group had good overall self-care practices. Also, there was statistically, significant difference within study group pre, and post-self-care practices educational intervention application. From the researcher's point of view, this improvement was due to the continuous follow-up of patients and re-demonstration of the self-care practices at regular intervals with continuous correction of missed or malpractices performed skills for both patients and their caregivers.

Also, patients were provided with a colored booklet illustrating different self-care practices to facilitate access to information when needed and to help them to remember. Furthermore, the researcher emphasized up on the importance of reinforcement of patients' self-care practices. The finding of this study was congruent with Umaefulam \& Premkumar (2020) who showed that the selfcare practices score of DR patients post implementation of the educational intervention was significantly increased.

Regarding overall self-care practices mean percent score, it was noticed that the Mean \pm SD for both studied groups were low pre-implementation of self-care practices educational intervention; while postimplementation of self-care practices educational intervention the Mean \pm SD for study group had improved dramatically. This may be due to the improvement of patients' knowledge reflecting on improving patients' self-care practices. This means that the selfcare practices educational intervention was effective in improving self-care practices of diabetic retinopathy patients.

\section{Conclusion}

It can be concluded that the studied patients who received self-care practices educational intervention had a significant improvement of knowledge and self-care practices than those who didn't receive it.

\section{Recommendations}

In line with the findings of the study, the following recommendations are made:

1. Provide Vitreoretinal Outpatient Clinic with enough qualified nurses to give diabetic retinopathy patients information about self-care practices.

2. In-service training programs and continuing education sessions have to be provided for nurses about diabetic retinopathy, its complications, treatment modalities, and nursing management

3. Study the effect of health teaching programs about self-care practices on the patients' 
Table (1) Frequency Distribution of Control and Study Group Patients with DR according to their Socio-demographic Data.

\begin{tabular}{|c|c|c|c|c|c|c|}
\hline \multirow[t]{2}{*}{ Socio-demographic Data } & \multicolumn{2}{|c|}{$\begin{array}{c}\text { Control group } \\
(n=30)\end{array}$} & \multicolumn{2}{|c|}{$\begin{array}{c}\text { Study group } \\
(\mathbf{n}=\mathbf{3 0})\end{array}$} & \multirow[t]{2}{*}{$\chi^{2}$} & \multirow[t]{2}{*}{$\mathbf{p}$} \\
\hline & No. & $\%$ & No. & $\%$ & & \\
\hline \multicolumn{7}{|l|}{ Age in Years } \\
\hline $18>30$ & & & 1 & 3.3 & \multirow{4}{*}{3.962} & \multirow{4}{*}{$\begin{array}{l}{ }^{M C} \mathrm{p}= \\
0.167\end{array}$} \\
\hline $30>40$ & & & 2 & 6.7 & & \\
\hline $40>50$ & 1 & 3.3 & 3 & 10.0 & & \\
\hline $50 \geq 60$ & 29 & 96.7 & 24 & 80.0 & & \\
\hline \multicolumn{7}{|l|}{ Gender } \\
\hline Male & 8 & 26.7 & 8 & 26.7 & \multirow{2}{*}{0.0} & \multirow{2}{*}{1.000} \\
\hline Female & 22 & 73.3 & 22 & 73.3 & & \\
\hline \multicolumn{7}{|l|}{ Level of Education } \\
\hline Illiterate & 13 & 43.3 & 8 & 26.7 & \multirow{6}{*}{3.132} & \multirow{6}{*}{$\begin{array}{l}{ }^{M C} \mathrm{p}= \\
0.715\end{array}$} \\
\hline Read and write & 4 & 13.3 & 3 & 10.0 & & \\
\hline Primary & 5 & 16.7 & 5 & 16.7 & & \\
\hline Preparatory & 2 & 6.7 & 4 & 13.3 & & \\
\hline Secondary & 4 & 13.3 & 7 & 23.3 & & \\
\hline University education and above & 2 & 6.7 & 3 & 10.0 & & \\
\hline \multicolumn{7}{|l|}{ Area of Residence } \\
\hline Rural & 11 & 36.7 & 10 & 33.3 & \multirow{2}{*}{0.073} & \multirow{2}{*}{0.787} \\
\hline Urban & 19 & 63.3 & 20 & 66.7 & & \\
\hline \multicolumn{7}{|l|}{ Marital Status } \\
\hline Single & & & 2 & 6.7 & \multirow{4}{*}{2.140} & \multirow{4}{*}{$\begin{array}{l}{ }^{M C} \mathrm{p}= \\
0.672\end{array}$} \\
\hline Married & 23 & 76.7 & 21 & 70.0 & & \\
\hline Divorced & 3 & 10.0 & 2 & 6.7 & & \\
\hline Widower & 4 & 13.3 & 5 & 16.6 & & \\
\hline \multicolumn{7}{|l|}{ Occupation } \\
\hline \multicolumn{7}{|l|}{ Employee } \\
\hline Professional & 1 & 3.3 & 3 & 10.0 & \multirow{5}{*}{3.536} & \multirow{5}{*}{$\begin{array}{l}{ }^{{ }^{M C}} \mathbf{p}= \\
0.504\end{array}$} \\
\hline Free work & 1 & 3.3 & 1 & 3.3 & & \\
\hline Housewife & 23 & 76.7 & 20 & 66.7 & & \\
\hline Retired & 3 & 10.0 & 1 & 3.3 & & \\
\hline Not working & 2 & 6.7 & 5 & 16.7 & & \\
\hline Monthly Income From Patient Po & & & & & & \\
\hline Not enough & 23 & 76.7 & 19 & 63.3 & & \\
\hline Enough & 7 & 23.3 & 10 & 33.4 & 1.842 & $\begin{array}{c}\mathrm{p}= \\
0.404\end{array}$ \\
\hline Enough and more & 0 & 0.0 & 1 & 3.3 & & \\
\hline Treatment System Cost & & & & & & \\
\hline State expenditure & 30 & 100.0 & 30 & 100.0 & - & - \\
\hline Health insurance & & & & & & \\
\hline \# Health Care Provider at Home & & & & & & \\
\hline Spouse & 16 & 53.3 & 12 & 40.0 & 1.071 & 0.301 \\
\hline Siblings & 12 & 40.0 & 13 & 43.3 & 0.069 & 0.793 \\
\hline Child & 1 & 3.3 & 2 & 6.7 & 0.351 & $\mathrm{FE}_{\mathrm{p}}=1.000$ \\
\hline Self & 5 & 16.7 & 3 & 10.0 & 0.577 & ${ }^{\mathrm{FE}_{\mathrm{p}}}=0.706$ \\
\hline
\end{tabular}


Table (2) Frequency Distribution of the Control and Study Group Patients with DR according to their Clinical Data.

\begin{tabular}{|c|c|c|c|c|c|c|}
\hline \multirow[t]{2}{*}{ Family history } & \multicolumn{2}{|c|}{$\begin{array}{l}\text { Control group } \\
(\mathbf{n}=\mathbf{3 0})\end{array}$} & \multicolumn{2}{|c|}{$\begin{array}{c}\text { Study group } \\
(\mathbf{n}=\mathbf{3 0})\end{array}$} & \multirow{2}{*}{$\chi^{2}$} & \multirow{2}{*}{$\mathbf{p}$} \\
\hline & No. & $\%$ & No. & $\%$ & & \\
\hline \multicolumn{7}{|c|}{ Is one of your family have a history of diabetes mellitus? } \\
\hline Yes & 25 & 83.3 & 24 & 80.0 & \multirow[t]{2}{*}{0.111} & \multirow[t]{2}{*}{0.739} \\
\hline No & 5 & 16.7 & 6 & 20.0 & & \\
\hline \# If yes & \multicolumn{2}{|c|}{$\mathbf{n}=\mathbf{2 5}$} & \multicolumn{2}{|c|}{$\mathrm{n}=\mathbf{2 4}$} & & \\
\hline Father & 8 & 32.0 & 8 & 33.3 & 0.010 & 0.921 \\
\hline Mother & 18 & 72.0. & 11 & 45.8 & 3.471 & 0.062 \\
\hline Brother /sister & 9 & 36.0 & 9 & 37.5 & 0.012 & 0.913 \\
\hline Grandfather/ Grand mother & 2 & 8.0 & 4 & 16.7 & 0.856 & ${ }^{\mathrm{FE}} \mathrm{p}=0.417$ \\
\hline \multicolumn{7}{|c|}{ Has he/she suffered from diabetic retinopathy? } \\
\hline Yes & 16 & 64.0 & 9 & 37.5 & \multirow[t]{2}{*}{3.441} & \multirow[t]{2}{*}{0.064} \\
\hline No & 9 & 36.0 & 15 & 62.5 & & \\
\hline \# If yes, Specify the affected individual? & \multicolumn{2}{|c|}{$(\mathrm{n}=16)$} & \multicolumn{2}{|c|}{$(\mathbf{n}=9)$} & & \\
\hline Father & 1 & 6.3 & 3 & 33.3 & 3.144 & ${ }^{F E} \mathrm{p}=0.116$ \\
\hline Mother & 10 & 62.5 & 2 & 22.2 & 3.744 & ${ }^{F E} \mathrm{p}=0.097$ \\
\hline Brother /sister & 6 & 37.5 & 7 & 77.8 & 3.744 & ${ }^{\mathrm{FE}} \mathrm{p}=0.097$ \\
\hline Grandfather/ Grand mother & 0 & 0.0 & 0 & 0.0 & - & - \\
\hline \multicolumn{7}{|c|}{ \# What are the complications of diabetic retinopathy your family experienced? } \\
\hline Retinal detachment & 0 & 0.0 & 2 & 22.2 & 4.547 & ${ }^{F E} \mathrm{p}=0.095$ \\
\hline Vitreous hemorrhage & 2 & 10.5 & 1 & 11.1 & 0.002 & ${ }^{F E} \mathrm{p}=1.000$ \\
\hline Glaucoma/cataract & 6 & 31.6 & 3 & 33.3 & 0.009 & ${ }^{\mathrm{FE}} \mathrm{p}=1.000$ \\
\hline Blindness & 5 & 26.3 & 3 & 33.3 & 0.147 & ${ }^{\mathrm{FE}} \mathrm{p}=1.000$ \\
\hline \multirow[t]{2}{*}{ Past history of the patient } & \multicolumn{2}{|c|}{$\begin{array}{c}\text { Control group } \\
(n=30)\end{array}$} & \multicolumn{2}{|c|}{$\begin{array}{c}\text { Study group } \\
(\mathrm{n}=\mathbf{3 0})\end{array}$} & \multirow{2}{*}{$\chi^{2}$} & \multirow{2}{*}{$\mathbf{p}$} \\
\hline & No. & $\%$ & No. & $\%$ & & \\
\hline \multicolumn{7}{|c|}{ Do you complain of any other health problems? } \\
\hline Yes & 23 & 76.7 & 24 & 80.0 & \multirow[t]{2}{*}{0.098} & \multirow[t]{2}{*}{0.754} \\
\hline No & 7 & 23.3 & 6 & 20.0 & & \\
\hline \# If the answer is yes, specify? & \multicolumn{2}{|c|}{$(n=23)$} & \multicolumn{2}{|c|}{$(n=24)$} & & \\
\hline Hypertension & 20 & 87.0 & 21 & 87.0 & 0.003 & ${ }^{\mathrm{FE}} \mathrm{p}=1.000$ \\
\hline Renal diseases & 3 & 13.0 & 2 & 8.3 & 0.274 & ${ }^{\mathrm{FE}} \mathrm{p}=0.666$ \\
\hline Liver diseases & 1 & 4.3 & 0 & 0.0 & 1.066 & ${ }^{F E} \mathrm{p}=0.489$ \\
\hline Pulmonary diseases & 3 & 13.0 & 2 & 8.3 & 0.274 & ${ }^{\mathrm{FE}} \mathrm{p}=0.666$ \\
\hline Cardiovascular diseases & 5 & 21.7 & 8 & 33.3 & 0.789 & 0.374 \\
\hline Have you ever been previously hospitalize & & & & & & \\
\hline Yes & 18 & 60.0 & 16 & 53.3 & 0.271 & 0.602 \\
\hline No & 12 & 40.0 & 14 & 46.7 & & \\
\hline \# If the answer is yes, specify the cause? & & 8) & & 6) & & \\
\hline Surgery & 9 & 50.0 & 13 & 81.3 & 3.622 & 0.057 \\
\hline Hypoglycemic coma & 1 & 5.6 & 1 & 6.3 & 0.007 & ${ }^{F E} \mathrm{p}=1.000$ \\
\hline
\end{tabular}




\begin{tabular}{|c|c|c|c|c|c|c|}
\hline Hyperglycemic coma & 5 & 27.8 & 4 & 25.0 & 0.034 & $\mathrm{FE}_{\mathrm{p}}=1.000$ \\
\hline Renal diseases & 3 & 16.7 & 0 & 0.0 & 2.925 & ${ }^{\mathrm{FE}} \mathrm{p}=0.230$ \\
\hline Cardiovascular diseases & 1 & 5.6 & 1 & 6.3 & 0.007 & ${ }^{\mathrm{FE}} \mathrm{p}=1.000$ \\
\hline \multicolumn{7}{|l|}{ Type of diabetes mellitus } \\
\hline Insulin dependent diabetes mellitus & 19 & 63.3 & 18 & 60 & \multirow[t]{2}{*}{0.071} & \multirow[t]{2}{*}{0.791} \\
\hline Non-insulin dependent diabetes mellitus & 11 & 36.7 & 12 & 40.0 & & \\
\hline \multicolumn{7}{|c|}{ When did you ask for medical help for the first time? } \\
\hline At the onset of DR symptoms & 22 & 73.3 & 16 & 53.4 & \multirow[t]{3}{*}{3.702} & \multirow{3}{*}{$\begin{array}{l}{ }^{{ }^{M C}} \mathrm{p}= \\
0.151\end{array}$} \\
\hline When symptoms were increased & 6 & 20.0 & 7 & 23.3 & & \\
\hline When you became unable to tolerate & 2 & 6.7 & 7 & 23.3 & & \\
\hline
\end{tabular}

\begin{tabular}{|c|c|c|c|c|c|c|}
\hline \multirow[t]{2}{*}{ Present history of the patient } & \multicolumn{2}{|c|}{$\begin{array}{l}\text { Control group } \\
(\mathbf{n}=\mathbf{3 0})\end{array}$} & \multicolumn{2}{|c|}{$\begin{array}{l}\text { Study group } \\
\quad(n=30)\end{array}$} & \multirow[t]{2}{*}{ Test of sig. } & \multirow[t]{2}{*}{$\mathbf{p}$} \\
\hline & No. & $\%$ & No. & $\%$ & & \\
\hline \multicolumn{7}{|c|}{ Since when did the complaint begin with diabetic retinopathy? } \\
\hline$<1$ & 4 & 13.3 & 10 & 33.3 & \multirow{3}{*}{$\chi^{2}=5.192$} & \multirow{3}{*}{$\begin{array}{l}{ }^{{ }^{M C}} \mathrm{p}= \\
0.083\end{array}$} \\
\hline $1-5$ & 19 & 63.4 & 18 & 60.0 & & \\
\hline$>5$ & 7 & 23.3 & 2 & 6.7 & & \\
\hline Min. - Max. & \multicolumn{2}{|c|}{$0.04-10.0$} & \multicolumn{2}{|c|}{$0.25-7.0$} & \multirow[t]{3}{*}{$\mathrm{U}=342.0$} & \multirow[t]{3}{*}{0.108} \\
\hline Mean \pm SD. & \multicolumn{2}{|c|}{$3.30 \pm 3.15$} & \multicolumn{2}{|c|}{$2.0 \pm 1.79$} & & \\
\hline Median & \multicolumn{2}{|c|}{2.0} & \multicolumn{2}{|c|}{1.50} & & \\
\hline \multicolumn{7}{|l|}{ Duration of your illness with diabetes (in years) } \\
\hline $1<5$ & 0 & 0.0 & 2 & 6.7 & \multirow{4}{*}{$\chi^{2}=2.154$} & \multirow[t]{4}{*}{0.707} \\
\hline $5<10$ & 2 & 6.7 & 3 & 10.0 & & \\
\hline $10<15$ & 4 & 13.3 & 4 & 13.3 & & \\
\hline 15 and more & 24 & 80.0 & 21 & 70.0 & & \\
\hline \multicolumn{7}{|l|}{ \# Chief complaint } \\
\hline Blurred vision & 23 & 76.7 & 25 & 83.3 & $\chi^{2}=0.417$ & 0.519 \\
\hline Seeing rings around lights & 0 & 0.0 & 1 & 3.3 & $\chi^{2}=1.017$ & $\mathrm{FE}_{\mathrm{p}}=1.000$ \\
\hline $\begin{array}{l}\text { The emergence of "spiders" or "threads of } \\
\text { spider" or small black spots floating in the } \\
\text { vision }\end{array}$ & 12 & 40.0 & 19 & 63.3 & $\chi^{2}=3.270$ & 0.071 \\
\hline Poor night vision & 5 & 16.7 & 7 & 23.3 & $\chi^{2}=0.417$ & 0.519 \\
\hline $\begin{array}{l}\text { Trouble in the transition from the bright } \\
\text { light to the pale light }\end{array}$ & 1 & 3.3 & 6 & 20.0 & $\chi^{2}=4.043$ & ${ }^{\mathrm{FE}} \mathrm{p}=0.103$ \\
\hline $\begin{array}{l}\text { Partial or total loss of vision (usually loss } \\
\text { of sight in both eyes, but one eye more than } \\
\text { the other) }\end{array}$ & 2 & 6.7 & 2 & 6.7 & $\chi^{2}=0.0$ & ${ }^{\mathrm{FE}} \mathrm{p}=1.000$ \\
\hline \multicolumn{7}{|l|}{ Others } \\
\hline Sensitivity to light & 0 & 0.0 & 1 & 3.3 & \multirow{2}{*}{$\chi^{2}=1.938$} & \multirow[t]{2}{*}{${ }^{\mathrm{FE}} \mathrm{p}=0.499$} \\
\hline Diffculty in reading & 0 & 0.0 & 1 & 3.3 & & \\
\hline \multicolumn{7}{|c|}{ Did you experience complications of diabetic retinopathy? } \\
\hline Yes & 19 & 63.3 & 18 & 60.0 & \multirow[t]{2}{*}{$\chi^{2}=0.071$} & \multirow[t]{2}{*}{0.791} \\
\hline No & 11 & 36.7 & 12 & 40.0 & & \\
\hline \# If the answer is yes, specify & \multicolumn{2}{|c|}{$(\mathbf{n}=19)$} & & & & \\
\hline Vitreous hemorrhage & 10 & 52.6 & 13 & 72.2 & $\chi^{2}=1.508$ & 0.219 \\
\hline Retinal detachment & 4 & 21.1 & 3 & 16.7 & $\chi^{2}=0.116$ & ${ }^{\mathrm{FE}} \mathrm{p}=1.000$ \\
\hline Glaucoma & 0 & 0.0 & 1 & 5.6 & $\chi^{2}=1.085$ & ${ }^{F E} \mathrm{p}=0.486$ \\
\hline Cataract & 8 & 42.1 & 6 & 33.3 & $\chi^{2}=0.302$ & 0.582 \\
\hline Blindness & 0 & 0.0 & 0 & 0.0 & - & - \\
\hline \# Prescribed medications & & & & & & \\
\hline Eye drops & 28 & 93.3 & 30 & 100.0 & $\chi^{2}=2.069$ & ${ }^{F E} \mathrm{p}=0.492$ \\
\hline Capsules & 3 & 10.0 & 8 & 26.7 & $\chi^{2}=2.783$ & 0.095 \\
\hline Anti angiogenic drug tablets & 3 & 10.0 & 6 & 20.0 & $\chi^{2}=1.176$ & ${ }^{F E}{ }_{p}=0.472$ \\
\hline
\end{tabular}


Table (3) Comparison between the Control and Study Group Patients with DR according to Total Patients' Knowledge Mean Percent Scores pre, and post implementation of self-care practices educational intervention

\begin{tabular}{|c|c|c|c|c|c|c|c|c|c|c|}
\hline \multirow{3}{*}{ Total Knowledge } & \multicolumn{4}{|c|}{$\begin{array}{l}\text { Control group } \\
\quad(\mathbf{n}=\mathbf{3 0})\end{array}$} & \multicolumn{4}{|c|}{$\begin{array}{l}\text { Study group } \\
\quad(\mathbf{n}=\mathbf{3 0})\end{array}$} & \multirow[t]{3}{*}{$\begin{array}{l}\text { Test of } \\
\left.\text { sig.(p } p_{1}\right)\end{array}$} & \multirow[t]{3}{*}{$\begin{array}{l}\text { Test of } \\
\operatorname{sig.}\left(p_{2}\right)\end{array}$} \\
\hline & \multicolumn{2}{|c|}{$\begin{array}{c}\text { Pre- } \\
\text { interventi } \\
\text { on }\end{array}$} & \multicolumn{2}{|c|}{$\begin{array}{l}\text { After } 3 \\
\text { months }\end{array}$} & \multicolumn{2}{|c|}{$\begin{array}{c}\text { Pre- } \\
\text { intervention }\end{array}$} & \multicolumn{2}{|c|}{$\begin{array}{c}\text { Post- } \\
\text { intervention }\end{array}$} & & \\
\hline & No. & $\%$ & No. & $\%$ & No. & $\%$ & No. & $\%$ & & \\
\hline Poor knowledge & 30 & $\begin{array}{c}100 . \\
0\end{array}$ & 30 & $\begin{array}{c}100 . \\
0\end{array}$ & 30 & 100.0 & 1 & 3.3 & \multirow[t]{3}{*}{-} & \multirow{3}{*}{$\begin{array}{c}\chi^{2}=67.156 \\
* \\
\left({ }^{\mathrm{MC}} \mathrm{p}<0.00\right. \\
\left.1^{*}\right)\end{array}$} \\
\hline Satisfactory knowledge & 0 & 0.0 & 0 & 0.0 & 0 & 0.0 & 3 & 10.0 & & \\
\hline Good knowledge & 0 & 0.0 & 0 & 0.0 & 0 & 0.0 & 26 & 86.7 & & \\
\hline Total score & \multicolumn{10}{|c|}{$(7-21)$} \\
\hline Min. - Max. & \multicolumn{2}{|c|}{$7.0-10.0$} & \multicolumn{2}{|c|}{$7.0-10.0$} & \multicolumn{2}{|c|}{$7.0-10.0$} & \multicolumn{2}{|c|}{$11.0-21.0$} & \multirow{11}{*}{$\begin{array}{l}\mathrm{U}=345.0 \\
0(0.103)\end{array}$} & \multirow{11}{*}{$\begin{array}{l}\mathrm{U}=0.00^{*} \\
\left(<0.001^{*}\right)\end{array}$} \\
\hline Mean \pm SD & \multicolumn{2}{|c|}{$7.90 \pm 0.96$} & \multicolumn{2}{|c|}{$8.0 \pm 1.05$} & \multicolumn{2}{|c|}{$8.30 \pm 1.06$} & \multicolumn{2}{|c|}{$19.0 \pm 2.63$} & & \\
\hline Median & \multicolumn{2}{|c|}{8.0} & \multicolumn{2}{|c|}{8.0} & \multicolumn{2}{|c|}{8.0} & \multicolumn{2}{|c|}{20.0} & & \\
\hline \multicolumn{9}{|l|}{ Mean score } & & \\
\hline Min. - Max. & \multicolumn{2}{|c|}{$1.0-1.43$} & \multicolumn{2}{|c|}{$1.0-1.43$} & \multicolumn{2}{|c|}{$1.0-1.43$} & \multicolumn{2}{|c|}{$1.57-3.0$} & & \\
\hline Mean \pm SD & \multicolumn{2}{|c|}{$1.13 \pm 0.14$} & \multicolumn{2}{|c|}{$1.14 \pm 0.15$} & \multicolumn{2}{|c|}{$1.19 \pm 0.15$} & 2.71 & \pm 0.38 & & \\
\hline Median & & & & & & 14 & & 86 & & \\
\hline$\%$ score & & & & & & & & & & \\
\hline Min. - Max. & $0.0-$ & 21.43 & $0.0-$ & 21.43 & 0.0 & 21.43 & 28.57 & -100.0 & & \\
\hline Mean \pm SD & 6.43 & 6.85 & 7.14 & 7.50 & 9.29 & \pm 7.54 & 85.71 & \pm 18.76 & & \\
\hline Median & & & & & & 14 & & .86 & & \\
\hline $\mathbf{Z}\left(\mathbf{p}_{\mathbf{0}}\right)$ & & 1.412 & $0.158)$ & & & $4.790^{*}$ & 0.001 & & & \\
\hline
\end{tabular}

$\mathrm{n}$ : number of studied patients

*: Statistically significant at $\mathrm{p} \leq 0.05$

$\chi^{2}$ : Chi-square FE: Fisher Exact

U: Mann Whitney test Z: Wilcoxon signed ranks test

$\mathrm{p}_{1}$ : $\mathrm{p}$-value for comparing between the studied groups in pre-intervention

$\mathrm{p}_{2}$ : $\mathrm{p}$-value for comparing between the studied groups in post-intervention

$\mathrm{p}_{0}$ : $\mathrm{p}$-value for comparing between before and after in each group 
Table (4) Comparison between the Control and Study Group patients regarding Overall Self-care Practices mean Percent Score pre, and post implementation of self-care practices educational intervention .

\begin{tabular}{|c|c|c|c|c|c|c|c|c|c|c|}
\hline \multirow{3}{*}{$\begin{array}{l}\text { Overall Self-care } \\
\text { Practices }\end{array}$} & \multicolumn{4}{|c|}{ Control group $(n=30)$} & \multicolumn{4}{|c|}{ Study group $(n=30)$} & \multirow{3}{*}{$\begin{array}{l}\text { Test of } \\
\operatorname{sig.}\left(p_{1}\right)\end{array}$} & \multirow{3}{*}{$\begin{array}{l}\text { Test of } \\
\text { sig.(p2) }\end{array}$} \\
\hline & \multicolumn{2}{|c|}{$\begin{array}{c}\text { Pre- } \\
\text { intervention }\end{array}$} & \multicolumn{2}{|c|}{$\begin{array}{l}\text { After 3 } \\
\text { months }\end{array}$} & \multicolumn{2}{|c|}{$\begin{array}{c}\text { Pre- } \\
\text { intervention }\end{array}$} & \multicolumn{2}{|c|}{$\begin{array}{c}\text { Post- } \\
\text { intervention }\end{array}$} & & \\
\hline & No. & $\%$ & No. & $\%$ & No. & $\%$ & No. & $\%$ & & \\
\hline Poor & 2 & 6.7 & 2 & 6.7 & 0 & 0.0 & 0 & 0.0 & \multirow{3}{*}{$\begin{array}{c}\chi^{2}=2.580 \\
\left({ }^{\mathrm{MC}} \mathrm{p}=0.493\right)\end{array}$} & \multirow{3}{*}{$\begin{array}{c}\chi^{2}=74.388^{*} \\
\left({ }^{\mathrm{MC}} \mathrm{p}<0.001^{*}\right)\end{array}$} \\
\hline Satisfactory & 28 & 93.3 & 28 & 93.3 & 29 & 96.7 & 0 & 0.0 & & \\
\hline Good & 0 & 0.0 & 0 & 0.0 & 1 & 3.3 & 30 & 100 & & \\
\hline \multicolumn{9}{|l|}{ Total score } & \multirow{12}{*}{$\begin{array}{c}\mathrm{U}=322.50 \\
(0.059)\end{array}$} & \multirow{12}{*}{$\begin{array}{c}\mathrm{U}=0.00^{*} \\
\left(<0.001^{*}\right)\end{array}$} \\
\hline Min. - Max. & \multicolumn{2}{|c|}{$88.0-115.0$} & \multicolumn{2}{|c|}{$88.0-122.0$} & \multicolumn{2}{|c|}{$82.0-126.0$} & \multicolumn{2}{|c|}{$121.0-171.0$} & & \\
\hline Mean \pm SD & \multicolumn{2}{|c|}{$101.53 \pm 6.74$} & \multicolumn{2}{|c|}{$\begin{array}{c}101.83 \\
\pm 7.41 \\
\end{array}$} & \multicolumn{2}{|c|}{$105.7 \pm 10.22$} & \multicolumn{2}{|c|}{$153.0 \pm 10.69$} & & \\
\hline Median & \multicolumn{2}{|c|}{102.0} & \multicolumn{2}{|c|}{101.50} & \multicolumn{2}{|c|}{104.50} & \multicolumn{2}{|c|}{154.0} & & \\
\hline \multicolumn{9}{|l|}{ Mean score } & & \\
\hline Min. - Max. & \multicolumn{2}{|c|}{$1.63-2.0$} & \multicolumn{2}{|c|}{$1.57-2.10$} & \multicolumn{2}{|c|}{$1.70-2.33$} & \multicolumn{2}{|c|}{$2.48-2.95$} & & \\
\hline Mean \pm SD & \multicolumn{2}{|c|}{$1.81 \pm 0.11$} & \multicolumn{2}{|c|}{$1.79 \pm 0.11$} & \multicolumn{2}{|c|}{$1.90 \pm 0.18$} & 2.68 & 0.11 & & \\
\hline Median & & & & & & & & & & \\
\hline$\%$ score & & & & & & & & & & \\
\hline Min. - Max. & 31.4 & -50.0 & 28.57 & 55.17 & 34.82 & 66.67 & 74.1 & 97.41 & & \\
\hline Mean \pm SD & 39.5 & \pm 5.64 & 40.45 & 5.39 & 44.96 & $=8.75$ & 83.8 & $=5.67$ & & \\
\hline Median & & & & & & & & & & \\
\hline $\mathbf{Z}\left(\mathbf{p}_{\mathbf{0}}\right)$ & & 1.841( & 066) & & & 4.782* & 0.001 & & & \\
\hline
\end{tabular}




\section{References}

- Achigbu, E., Oputa, R., Achigbu, K., \& Ahuche, I. (2016). Knowledge, attitude and practice of patients with diabetes regarding eye care. Open Journal of Ophthalmology, 6(2) 94102.

- Al baiuomy,M.E., Bedier, N.A., \& Abd El Hafeez, N.A. (2019). Self care practices among patients with diabetic retinopathy. IOSR Journal of Nursing and Health Science, 8(5),3343. DOI: 10.9790/1959-0805103343.

- Albikawi, Z., \& Abuadas, M. (2015). Diabetes self-care management behaviors among Jordanian type two diabetes patients. American International Journal of Contemporary Research, 5(3),87.

- Al Shibli, J ., Mukhlif, Z, \& Al Moqbali, J. (2018). Knowledge, attitude and barriers

towards self-care practices in patients with diabetes mellitus in North Batinah, Sultanate of

Oman Firdous. International Journal of Public Health Research, 6(3), 63-70.

- Al Zarea, B. (2016). Knowledge, attitude and practice of diabetic retinopathy amongest the diabetic patients of AlJouf and Hail Province of Saudi Arabia. J Clin Diagn Res, 10(5): 5-8.

- American Academy of Ophthalmology. (2014). Diabetic retinopathy preferred practice pattern. Retrieved from http://one.aao.org/preferredpracticepattern/diabetic-retinopathyppp--2014.

- American Academy of Ophthalmology. (2021). Diabetic retinopathy. Retrieved from

https://www.aao.org/topic-detail/diabeticretinopathy-middle-east.

- American Diabetes Association. (2014). Standards of medical care in diabetes. Diabetes Care, 37(1),1480.
- American Diabetes Association. (2019). Eye complications. Retrieved from: https://www.diabetes.org .

- American Diabetes Association. (2020). Obesity management for the treatment of type 2 diabetes: standards of medical care in diabetes. Diabetes Care,43(1), 89-97.

- American Diabetes Association. (2020). Pharmacologic approaches to glycemic treatment: standards of medical care in diabetes. Diabetes Care,43(1), 98-110.American Optometric Association. (2019). Diabetic retinopathy. Retrieved from:https://www.aoa.org.

- Baumal, C.R., \& Duker, J.S.(2018). Current management of diabetic retinopathy $\left(1^{\text {st }} e d\right)$.

[e.book]. Retrieved from https://doi.org/10.1016/C2009-0-41769-0.

- Bhavsar, A., \& Khardori, R. (2020). What is the follow-up care in the treatment of diabetic retinopathy. Retrieved from https://www.medscape.com/answers/ 1225122-100746/what-is-the-followup-care-in-the-treatment-of-diabeticretinopathy.

- Dai, X., Zhai, L., \& Chen, Q. (2019). Two-year-supervised resistance training prevented diabetes incidence in people with pre-diabetes: a randomized control trial. Diabetes Metab Res Rev, 35(1), 3143.

- Deak, M., Lasca, M., \& Veresiu, I. (2015). Risk factors for diabetic retinopathy progression. Romanian Journal of Diabetes Nutrition and Metabolic Diseases, 22(2), 159-165.

- Demmitt, A. (2015). Diabetes education can help lowering blood sugars and reduce the risk of diabetic retinopathy. Retrieved from http://www.visionaware.org.

- Diabetes State/Territory Organizations. Diabetes and eyes. (2012). Retrieved from http://diabetesnsw.com.au. 
- Duan, F., Liu, Y., Chen, X., Congdon, N., Zhang, J., Chen, Q.........\& Liu, Y. (2017). Influencing factors on compliance of timely visits among patients with proliferative diabetic retinopathy in southern China: a qualitative study. BMJ Journals, 7(3): 13578.

- Duffy, M. (2017).Vision aware for independent living with vision loss: vision rehabilitation services. Retrieved from: http://www.visionaware.org.

- Fenwick, E., Pesudovs, K., Khadka J., Dirani, M., Rees, G., Wong, T.Y., \& Lamoureux,E.L. (2012). The impact of diabetic retinopathy on quality of life. Qual Life Res, 21, 1771-1782.DOI: $\quad 10.1007 / \mathrm{s} 11136-$ 012-0110-1.

- Funnell, M.M., Brown, T. L., Childs, B. P., Haas, L. B., Hosey, G. M., Jensen, B., Maryniuk, M., Peyrot, M., Piette, J.D., Reader, D., Siminerio, L.M., Weinger, K., \& Weiss, M.A. (2012). National standards for diabetes selfmanagement education. Diabetes Care, 35(1), 101-108.

- Harkins, V. (2008). A practical guide to integrated type 2 diabetes care. Retrieved from: http://www.hse.ie.

- Hartayu,T.S., Izham, M., \& Sri Suryawati, S. (2012). Improving of type 2 diabetic patients' knowledge, attitude and practice towards diabetes self-care by implementing community-based interactive approach-diabetes mellitus strategy. BMJ Journals, 5(5): 315.

- Hazavehei,S.M.M., Jeihooni, A.K., Hasanzadeh, A., \& Amini,S. (2010).The effect of educational program based on basnef model for eye care in non-insulin dependent diabetic patients. Journal of Research in Health Sciences, 10(2):81-90.

- Hosseini,s.s., Shamsi,M., Khorsandi, M.\& Moradzadeh, R. (2021). The effect of educational program based on theory of planned behavior on promoting retinopathy preventive behaviors in patients with type 2 diabetes: RCT. BMC Endocrine Disorders, 21(17).

- Imai, H., Honda, S., Tsukahara, Y., \& Negi, A.(2011). Retinopathy Case Report .Ophthalmol,2(1), 314-318.

- International Centre for Eye Health. (2016). Diabetic retinopathy (DR): management and referral. Comm Eye Health, 28(92),70 - 71.

- Jesus, C. (2012). Diabetic retinopathy. Retrieved from: http://www.intechopen.com/books/di abetic-retinopathy/diabetic retinopathy.

- Khalaf, F.R., Fahmy, H.M., Ibrahim,A.K.,Mohamed,G.A., $\quad$ Ez Eldeen,M.E., Elkady,A.,\& Hetta, H.F. (2019). Does a diabetic retinopathy educational program raise awareness among elderly diabetic patients? Diabetes Metab Syndr Obes.,12: 1867-1875. doi: 10.2147/DMSO.S208072.

- Kumar, K.B., Bhowmik,D., Harish,G., Duraivel,S., \& kumar, B.P. (2012). Diabetic retinopathysymptoms, causes, risk factors and treatment. Pharma Innovation Journal, 1(8):7-13.

- Lee, R., Wong, T.Y., \& Sabanayagam, C. (2015). Epidemiology of diabetic retinopathy, diabetic macular edema and related vision loss. Eye Vis., 2(1),1-25. doi:10.1186/s40662-0150026-2.

- Macky, T.A, Khater, N., Al-Zamil, M., El Fishawy, H. \& Soliman, M. (2011). Epidemiology of diabetic retinopathy in Egypt. Ophthalmic Res, 45(2):73-78.doi: 10.1159/000314876.

- Mitchell, P., \& Wong, T.Y. (2014). Management paradigms for diabetic macular edema. American Journal of Ophthalmology, 157(3), 505-513.

- Mohamed, S.S., Mohamed, R.F., \& Mohamed, S.H. (2019). Impact of 
educational intervention program on diabetic retinopathy patient's compliance. American Journal of Nursing Research., 7(6), 1000-1008. DOI: 10.12691/ajnr-7-6-14.

- Najee, \& Shakir. (2019).Effectiveness of an instructional program on knowledge of type 2 diabetic patient toward ocular self-care at diabetic and endocrine center in Al-Nasiriya City. Indian Journal of Forensic Medicine \& Toxicology, 13(4):929.

- National Eye Institute. (2019). Diabetic retinopathy. Retrieved from https://www.nei.nih.gov/learn-abouteye-health/eye-conditions-anddiseases/diabetic-retinopathy.

- NHS. (2021). Treatment of Diabetic retinopathy. Retrieved from https://www.nhs.uk/conditions/diabet ic-retinopathy/treatment/.

- Nordqvist,C. (2015). Diabetic retinopathy: causes, symptoms and treatments. Retrieved from http://www.medicalnewstoday.org.

- Rodriguez-Acuña, R., Mayoral, E., Aguilar-Diosdado, M., Rave, R., Oyarzabal, B., Lama, C., Carriazo, A., Martinez-Brocca, M.A. (2020). Andalusian program for early detection of diabetic retinopathy: implementation and 15-year followup of a population-based screening program in Andalusia, Southern Spain. BMJ Open Diabetes Research \& Care, $8(1), 1$.

- The International Council of Ophthalmology (ICO). (2017). ICO Guidelines for diabetic eye care. Retrieved from: http://www.icoph.org/downloads/IC OGuidelinesforDiabeticEyeCare.pdf.

- The Johns Hopkins University.(2021). Self-monitoring of blood glucose. Retrieved from:https://hopkinsdiabetesinfo.org/ self-monitoring-of-blood-glucose/.

- The Royal College of Ophthalmologists. (2012). Diabetic retinopathy guidelines. Royal
College of Ophthalmologists, London.

- Sabanayagam, C., Banu, R., Chee, M.L., Jonas, J.B., Lamoureux,E.L., Cheng ,C.Y., Klein,B.E.K., Mitchell, P., Klein, R., Cheung C.M.G., \&

- Umaefulam, V., \& Premkumar, K. (2020). Impact of mobile health in diabetic retinopathy awareness and eye care behavior among Indigenous women. Mhealth,6(14). doi: $10.21037 /$.

- Viswanath, K., \& McGavin, D. (2003). Diabetic retinopathy: clinical findings and management. Community Eye Health, 16(46),2124.

- Weinstock, R.S. (2020). Patient education: type I diabetes: insulin treatment (Beyond the Basics). Retrieved from: https://www.uptodate.com/contents/t ype-1-diabetes-insulin-treatmentbeyond-the-basics/print.

- World Health Organization. (2013). Universal eye health: a global action plan 2014-2019, Geneva.

- Wong, T.Y. (2018) Incidence and progression of diabetic retinopathy: a systematic review. The lancet. Diabetes \& Endocrinology,7(2):140149.DOI: $10.1016 / \mathrm{s} 2213$ 8587(18)30128-1

- Wong, T.Y., \& Sabanayagam, C . (2019). The war on diabetic retinopathy: where are we now? Asia Pac J Ophthalmol (Phila), 8 (6), 448-456.

- Wood, D. (2010). 10 Behavior modification tips for nurses: How to help patients help themselves. Retrieved from http:// www.nursezone.com/Nursing-NewsEvents/more-news/10-BehaviorModification-Tips-for-Nurses-How toHelp- Patients-Help-Themselves 34358 aspx. 